\title{
FISHING PATTERN AND INTERACTIONS OF FLEET COMPONENTS IN THE ARGYROPS SPINIFER (ACTINOPTERYGII: PERCIFORMES: SPARIDAE) FISHERIES OF THE ARABIAN SEA, OMAN
}

\author{
Juma Al-MAMRY ${ }^{1}$, Sadok BEN MERIEM ${ }^{2 *}$, Ian D. McCARTHY ${ }^{3}$, \\ and Christopher A. RICHARDSON ${ }^{3}$ \\ ${ }^{1}$ Marine Sciences and Fisheries Center, Ministry of Fisheries Wealth, PO Box 427, Code100, \\ Muscat, Sultanate of Oman \\ ${ }^{2}$ Institut National des Sciences et Technologies de la Mer (INSTM), 2016 Salammbô, Tunisia \\ ${ }^{3}$ School of Ocean Sciences, College of Natural Sciences, Bangor University, Menai Bridge, \\ Anglesey, LL59 5AB. United Kingdom
}

Al-Mamry J., Ben Meriem S., McCarthy I.D., Richardson C.A. 2011. Fishing pattern and interactions of fleet components in the Argyrops spinifer (Actinopterygii: Perciformes: Sparidae) fisheries of the Arabian Sea, Oman. Acta Ichthyol. Piscat. 41 (1): 55-62.

\begin{abstract}
Background. The influx of foreign fishing vessels in the Arabian Sea, during the mid 1990's, has sparked some conflicts between artisanal and industrial fleets and raised concerns related to the resource management implications of fish stocks in the region. To address the lack of management data on the basic biology and stock assessment for targeted species, the Ministry of Fisheries Wealth in Oman initiated this study with a view to contributing towards the development of a management plan for the sustainable exploitation of the living resources of the sea in this region.

Materials and methods. A database including biological parameters, length-frequency distributions and catches of king soldier bream, Argyrops spinifer (Forsskål, 1775), in Oman according to fleet (gear/technique) and region was compiled by monthly sampling in 2001 to 2002. In this study, length cohort and yield per recruit analyses were examined after simulating changes in fishing effort, in length at first capture and introducing a closed season for trawlers. Results. The results showed that: (i) the status of the stock is healthy, the average fishing mortality rate is moderate $(0.1)$ and acts in general on the adult fraction of the stock. The fishing pattern differs, however, among fleets with some fleet components fishing, in part, for immature king soldier bream. (ii) An increase in total fishing effort would not lead to any long-term substantial increase of the catch (according the uncertainty of $M$ value); however, the spawning stock biomass would decrease significantly. This measure affects negatively fleets that target the larger specimens. (iii) A moderate $( \pm 20 \%)$ modification of minimum length limit in catches would not affect, substantially, the sustainable yield and the spawning stock biomass. (iv) Any regulation of trawler fishing by closed season (i.e. restricted trawler activities during some seasons) would not have a significant effect on the long-term yield. Conclusion. The current pattern of exploitation and fishing effort acting on the A. spinifer stock are optimal and no changes to global fishing or length at first capture are recommended. Also, with the actual fishing effort of trawlers, no closed season is suggested. However, fleet components whose catches include some juvenile fraction should adopt more selective gear as used by the hand line fishery in the Al-Wusta region.
\end{abstract}

Keywords: Argyrops spinifer, stock assessment, fisheries management Arabian Sea, Oman

\section{INTRODUCTION}

The king soldier bream, Argyrops spinifer (Forsskål, $1775)$ is widespread in the Indo-West Pacific, where adults occur mostly between 30-100 m of depth, over a range of bottom types (Randall 1995). A. spinifer is a relatively large sparid; it is characterized by a long life span and low growth rate (Ben Meriem et al. 2004, Al-Mamry et al. 2009, Al-Mamry unpublished**). It attains a maxi- mum size of $70 \mathrm{~cm}$ total length and age of approximately 25 years (Al-Mamry et al. 2009) and is probably protogynous, undergoing a sex reversal from female to male after a certain age (Grandcourt et al 2004, McIlwain et al. 2006, Al Mamry unpublished**). The species spawns each year between October and December and the size at first maturity is around $37 \mathrm{~cm}$ total length (Ben Meriem et al. 2004, Al-Mamry et al. 2009). Sea breams are economically

\footnotetext{
* Correspondence: Dr. Sadok Ben Meriem, Institut National des Sciences et Technologies de la Mer (INSTM), 2016 Salammbô, port de peche, Tunisia, phone: +216 71735848 , fax: +216 71735848 , e-mail: sadokbm@yahoo.fr

** Al-Mamry J.M. 2006. Biology and fisheries management of king soldier bream, Argyrops spinifer and spangled emperor, Lethrinus nebulosus in the Arabian Sea, Oman. PhD Thesis. University of Wales, Bangor, UK
} 
important demersal species along the Arabian Sea coast of Oman. Between 1994 and 2003 the landings of all sea breams (including $A$. spinifer) fluctuated between 4000 and $9000 \mathrm{t}$ per year (average of $5000 \mathrm{t}$ per year) (Anonymous 2003). A. spinifer is one of the most important species in the demersal Omani fisheries and constitutes one of the most common sparids landed in Oman (around $800 \mathrm{t}$ per year).

The fisheries of $A$. spinifer are located along the Arabian Sea coast of Oman (Sharqia, Al-Wusta and Dhofar regions; Fig. 1). It is exploited in inshore waters throughout its range; artisanal fisheries contribute around $3 / 4$ of the total catch and with the rest of the catch landed by an industrial fishery (trawlers). Exploitation is based on six fleet components; fishing traps and hand lines are used by artisanal fleets in Dhofar and Sharqia regions, while in Al-Wusta region only hand lines are used. The industrial fleet uses exclusively bottom trawling gear. The latter fishery is limited to fishing grounds further than 10 nautical miles from the coast and/or a minimum depth of $50 \mathrm{~m}$. Therefore, the exploitation pattern may differ among fleet components depending on fishing region, gears, and techniques used and could lead to some interactions in the fisheries for this species.

The influx of fishing vessels, especially foreign trawlers from Korea and Taiwan, during the mid 1990's, has generated some conflicts between artisanal and industrial fleets and raised concerns relating to resource management in the Arabian Sea. Confronting this problem, the Ministry of Fisheries Wealth in Oman decided in the late 1990's to limit the access of trawlers to the fishery and the number of trawlers operating in the Arabian Sea had been substantially reduced (from 60 to 5 trawlers) by the beginning of 2000 . At the same time, the Ministry initiated a research project in order to carry out, for the first time, a stock assessment of the seven main species in the demersal fisheries in Oman with $A$. spinifer being one of those species.

The aim of this study is to provide the first detailed assessment of the fisheries for A. spinifer in the Arabian Sea by: (1) assessing the exploitation status of the species by the different fisheries in the region and (2) providing the necessary information required for stock assessment of the species and for management of its fisheries through the use of length cohort analysis (LCA) based on the demographic structure of the $A$. spinifer catch and biological parameters for the species.

\section{MATERIALS AND METHODS}

Definition of fleet components. Six fleet components are identified in the $A$. spinifer fishery in Oman: the first group was formed by small artisanal boats of around $5.5-7.5 \mathrm{~m}$ (18-24 feet) in length. This group is separated into five components: for the Sharqia and Dhofar regions (Fig. 1), the fleets were separated into 2 components, hand lines and fishing traps respectively, whilst only hand lines are used in the Al-Wusta region. The second is constituted by large industrial fishing boats $(>40 \mathrm{~m})$ that use demersal fishing gear (trawl). These different fleet components were abbreviated as follows:

- Industrial trawlers: TRAWL

- Artisanal boats in the Sharqia region using fishing traps: SHAFT.

- Artisanal boats in the Sharqia region using hand lines: SHAHL.

- Artisanal boats in the Dhofar region using fishing traps: DHOFT.

- Artisanal boats in the Dhofar region using hand lines: DHOHL.

- Artisanal boats in the Al-Wusta region using hand lines: WUSHL.

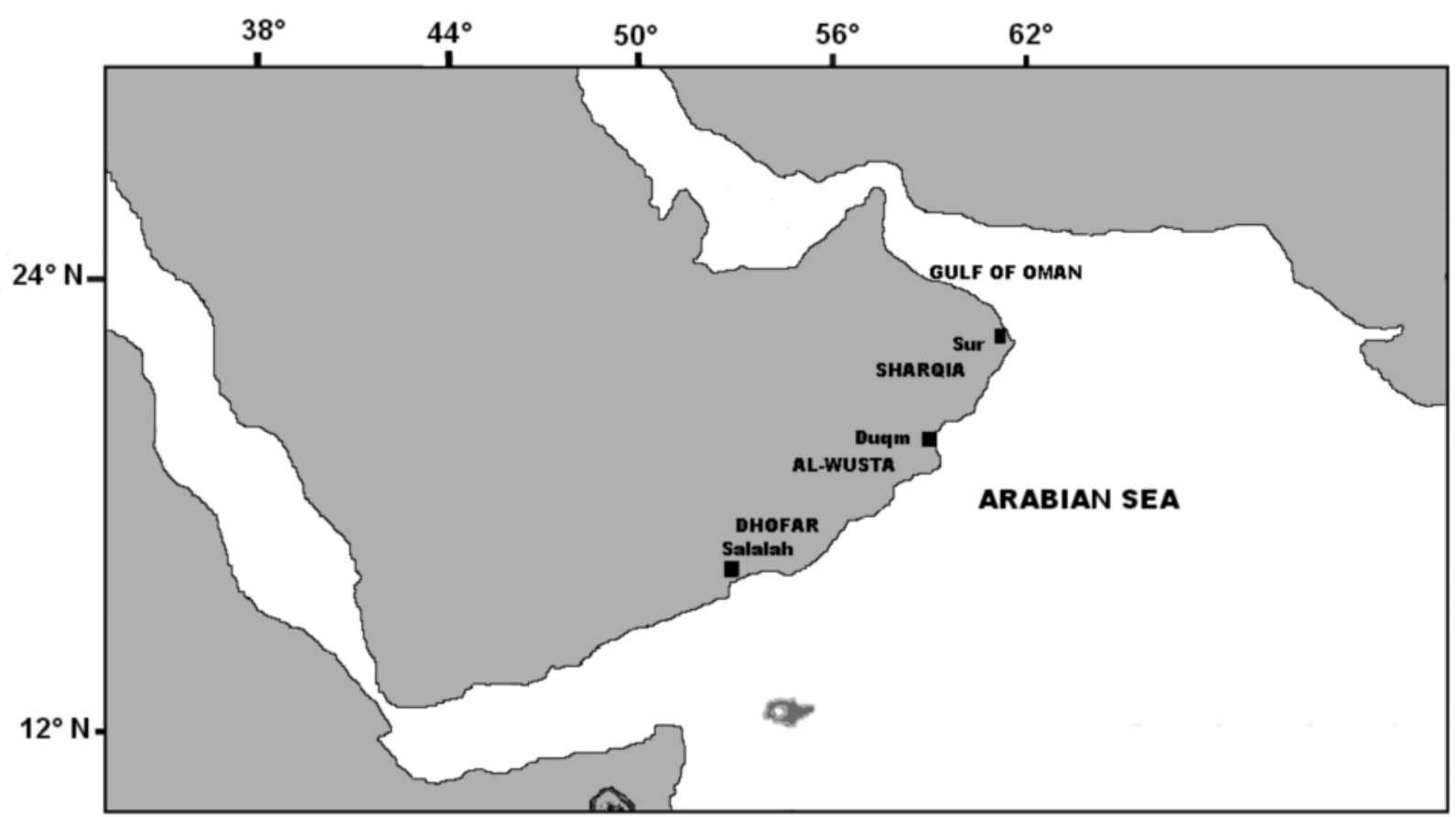

Fig. 1. Map of Argyrops spinifer fishing regions and sampling sites in Oman 
The relative contributions to the total catch of these 6 fleet components are $27 \%, 23 \%, 16 \%, 13 \%, 11 \%$, and $10 \%$, respectively.

Catch data and length frequency distributions. It is important to stress that catch is synonymous to landing because there are no discards for this species. The catch per fishing gear data was obtained from the Omani Fisheries Statistics Department for the period of 2001-2002 (Ministry of Fisheries Wealth, Anonymous 2002, 2003). These data were collected for each type of fishing gear separately, and from all defined fishing boats operating in either the artisanal fishery or the industrial fishery in the Arabian Sea. For each of the traditional fishing gears (fleets), a number of boats (5-15 boats) were sampled every month by data collectors. For the industrial fleets, the catch was recorded on board. In each trawl boat, one or two observers monitored the trawling and recorded the catch (landing) and fishing effort.

The length frequencies of $A$. spinifer were obtained from 6 fleet components (Table 1) that contribute significantly to the exploitation of the species, based on length samples collected during the demersal fish project conducted by the Marine Sciences and Fisheries Center over a two year period between 2001 and 2002. Random samples were taken monthly for each fishing gear/technique utilized. The fish length sampling program covered the three regions which contribute to the traditional A. spinifer fishery: Sharqia, Al-Wusta, and Dhofar (Fig. 1); the total length measured to the nearest $\mathrm{cm}$ for around 200 randomly sampled fish per month, per site, for each gear identified above. To estimate the demographic structures of the whole catches, length frequency samples were extrapolated to the total landing per fleet and fishing region (Table 1). Also, length frequencies (pooled from monthly data) for each quarter of the year were prepared separately for trawlers in order to simulate the impact of a closed season on this fleet.

Biological parameters. Parameter estimates used in the length cohort analysis are taken from the biological studies on $A$. spinifer in Omani waters; including vonBertalanffy growth curves $\left(L_{\infty}, K\right.$, and $\left.t_{0}\right)$, length-weight relations, length at sexual maturity $\left(L_{50}\right)$, natural mortality $(M)$, and selectivity factor (SF). The parameters estimates used in the present study are:

- $L_{\infty}$ (asymptotic length) $=64 \mathrm{~cm}$ (Al-Mamry et al. 2009);

- $K$ (growth coefficient) $=0.14$ (Al-Mamry et al. 2009);

- SF: 3.5 (Anonymous unpublished ${ }^{*}$ ); This value is used for artisanal fishing gear in Al-Wusta and Dhofar;

- $L_{50}=37 \mathrm{~cm}$ (Ben Meriem et al. 2002a);

- Length-weight relation: $W=7.03 \times 10^{-8} \times \mathrm{L}^{2.61}(\mathrm{Ben}$ Meriem et al. 2002b);

- $M=0.38$ (this study).

Natural mortality. The value obtained in this study should be considered as a preliminary estimation. Natural mortality was obtained from the equation:

$\log (M)=-0.0066-0.279 \log \left(L_{\infty}\right)+0.6543 \log (K)+0.4634 \log (T)$ (Pauly 1980) with $T$ indicating the mean temperature of the water $\left(25.56^{\circ} \mathrm{C}\right.$, Hydrographic Survey in Oman waters, unpublished data). The equation gives a value of 0.38 for $M$; this value was adopted in the present stock assessment. Also, a sensitivity analyses to this parameter was carried out, especially in case of overestimation of $M$, on LCA results. For this analysis a value of $M=0.2$ is tested.

Length cohort analysis (LCA). Sparre and Venema (1992) and Jones (1981) provide a clear description of the LCA methods used in this study. This analysis supposes that the stock is in equilibrium state: i.e., with constant recruitment, $F$ and $M$ vectors. To attenuate the effect of the eventual variation of the exploitation pattern and/or the recruitment intensity, an average of the size distributions obtained over a period of two years (2001 and 2002) were therefore used.

Length cohort analysis was applied to estimate the fishing mortality and abundance vectors by length class. The length $(L+)$, from which calculations of fishing mortalities are initiated, has been determined according to the recommendations of Pereiro and Pallares (1984) who recommended using a "group+" around $70 \%$ of $L_{\infty}$ (in this study $L+$ is $45 \mathrm{~cm}$ ). However, since in this study the numbers of fish larger than $70 \%$ of $L_{\infty}$ have a significant importance in the catch length distributions, $L+$ was set to $54 \mathrm{~cm}$ in the present analysis. It is generally considered, that the value of $F_{t}$ fixed for the group + must be in continuity (i.e., a similar value) with the fishing mortalities of the previous size groups. The catches in number are estimated by fleet, and results are also presented for the global balance and by fleet component.

Exploitation pattern. For each fish length, the fishing mortality fraction of the fleet $\mathrm{j}$ could be estimated according to the contribution of this fleet to the total catch. Considering $C_{i}$ and $F_{i}$ be the total catch of $A$. spinifer and fishing mortality of the length class $i, C_{i, j}$ and $F_{i, j}$ are the contribution of the fleet $\mathrm{j}$ respectively. The estimation of the fishing mortality per fleet component is based on the following equations.

$$
\begin{gathered}
F_{i, j} / F_{i}=C_{i, j} / C_{i} \\
F_{\mathrm{i}}=\sum_{j=1}^{n} F_{\mathrm{i}, j} \quad C_{\mathrm{i}}=\sum_{j=1}^{n} C_{\mathrm{i}, j}
\end{gathered}
$$

Where $\mathrm{n}$ is the number of fishing fleet components participating in the exploitation of the A. spinifer fishery in Omani waters.

Yield-per-recruit model. This analysis, using the Jones (1974) model of yield per recruit, investigated the impact of modifications of the fishing effort, minimum (first) catch size and fish closing season regulations for trawlers on the yield per recruit. It should be noted that, any modification of effort, first length in catches or period of closing season has both an immediate impact (immediately) and long-term effects (sustainable) which occur after the new equilibrium conditions of the stock have been established. For this analysis, the ANALEN (analyses data by size class) software program was used. This software was elaborated upon by Chevallier and Laurec (1990). The stock biomass is calculated from the length-weight relation and the abundance $(N)$ per length class. The spawning stock biomass is derived by applying $L_{50}$ to the number of survivors.

\footnotetext{
* Anonymous: Gears and techniques in Oman artisanal fishery
} 
Table 1

Catch (number of individuals) of Aryrops spinifer per fishing fleet in the Arabian Sea n 2001-2002

\begin{tabular}{|c|c|c|c|c|c|c|c|}
\hline \multirow{2}{*}{ Length class $[\mathrm{cm}]$} & \multicolumn{7}{|c|}{ Fishing fleet } \\
\hline & DHOFT & DHOHL & TRAWL & WUSHL & SHAHL & SHAFT & Total \\
\hline 9 & 0 & 0 & 57 & 0 & 0 & 0 & 57 \\
\hline 10 & 0 & 0 & 86 & 0 & 0 & 0 & 86 \\
\hline 11 & 0 & 0 & 175 & 0 & 0 & 0 & 175 \\
\hline 12 & 0 & 0 & 284 & 0 & 0 & 0 & 284 \\
\hline 13 & 51 & 0 & 296 & 0 & 0 & 0 & 347 \\
\hline 14 & 202 & 0 & 243 & 0 & 0 & 0 & 446 \\
\hline 15 & 202 & 96 & 156 & 0 & 0 & 0 & 454 \\
\hline 16 & 405 & 288 & 476 & 0 & 0 & 0 & 1169 \\
\hline 17 & 455 & 669 & 1187 & 0 & 0 & 0 & 2311 \\
\hline 18 & 607 & 772 & 1100 & 0 & 0 & 32 & 2511 \\
\hline 19 & 455 & 2574 & 1587 & 0 & 0 & 97 & 4714 \\
\hline 20 & 1730 & 3260 & 2109 & 0 & 0 & 289 & 7389 \\
\hline 21 & 2201 & 2052 & 1557 & 0 & 171 & 217 & 6196 \\
\hline 22 & 3765 & 1619 & 3138 & 0 & 513 & 362 & 9397 \\
\hline 23 & 5480 & 1526 & 4234 & 0 & 1539 & 362 & 13141 \\
\hline 24 & 5136 & 1329 & 3688 & 0 & 2936 & 426 & 13510 \\
\hline 25 & 5991 & 1242 & 3049 & 45 & 4303 & 1306 & 15936 \\
\hline 26 & 6823 & 2522 & 4745 & 112 & 9893 & 2459 & 26555 \\
\hline 27 & 7904 & 4473 & 4717 & 195 & 11026 & 3936 & 32249 \\
\hline 28 & 7136 & 7132 & 5779 & 409 & 10066 & 6736 & 37259 \\
\hline 29 & 7927 & 11124 & 6324 & 552 & 7949 & 11702 & 45595 \\
\hline 30 & 6762 & 13576 & 6940 & 729 & 6843 & 13226 & 48076 \\
\hline 31 & 5355 & 15962 & 5055 & 867 & 6478 & 18675 & 52391 \\
\hline 32 & 4686 & 12230 & 3776 & 1059 & 6302 & 21880 & 49934 \\
\hline 33 & 3269 & 9226 & 6194 & 552 & 5884 & 14903 & 40028 \\
\hline 34 & 2698 & 6659 & 6662 & 596 & 8278 & 9738 & 34631 \\
\hline 35 & 2441 & 3323 & 8208 & 851 & 8836 & 8994 & 32654 \\
\hline 36 & 2020 & 1960 & 11160 & 989 & 7592 & 9194 & 32915 \\
\hline 37 & 2747 & 1321 & 7861 & 948 & 6720 & 7454 & 27050 \\
\hline 38 & 2756 & 1346 & 7238 & 914 & 6875 & 8105 & 27234 \\
\hline 39 & 2651 & 373 & 5258 & 1397 & 4927 & 8092 & 22697 \\
\hline 40 & 3248 & 139 & 6766 & 1554 & 4650 & 7016 & 23373 \\
\hline 41 & 4096 & 127 & 6819 & 1755 & 3917 & 4862 & 21575 \\
\hline 42 & 2631 & 70 & 7746 & 1652 & 2874 & 4362 & 19336 \\
\hline 43 & 23013 & 394 & 6452 & 1562 & 3057 & 2426 & 15903 \\
\hline 44 & 2551 & 737 & 5284 & 1869 & 2333 & 3060 & 15835 \\
\hline 45 & 2880 & 1729 & 4448 & 2181 & 2608 & 2144 & 15991 \\
\hline 46 & 4849 & 1211 & 3633 & 1971 & 1856 & 1641 & 15161 \\
\hline 47 & 2619 & 987 & 4247 & 2072 & 1569 & 1409 & 12903 \\
\hline 48 & 2530 & 875 & 4184 & 2056 & 1231 & 1356 & 12232 \\
\hline 49 & 1056 & 986 & 4129 & 2542 & 1066 & 1500 & 11279 \\
\hline 50 & 638 & 521 & 3674 & 3091 & 743 & 1841 & 10508 \\
\hline 51 & 582 & 824 & 4300 & 2861 & 883 & 1360 & 10810 \\
\hline 52 & 422 & 1013 & 3948 & 2989 & 575 & 2165 & 11112 \\
\hline 53 & 261 & 663 & 3423 & 3011 & 571 & 1475 & 9404 \\
\hline 54 & 330 & 488 & 3480 & 2456 & 346 & 2046 & 9150 \\
\hline 55 & 255 & 399 & 3317 & 1858 & 319 & 1396 & 7544 \\
\hline
\end{tabular}

Abbreviations: TRAWL = Industrial trawlers; SHAFT $=$ artisanal boats in the Sharqia region using fishing traps; SHAHL $=$ artisanal boats in the Sharqia region using hand lines; DHOFT = artisanal boats in the Dhofar region using fishing traps; DHOHL = artisanal boats in the Dhofar region using hand lines; WUSHL = artisanal boats in the Al-Wusta region using hand lines. 
Simulations. Changes in following parameters were considered in the simulations:

Modification of the fishing effort: simulation variation in total effort in the same proportion for the different fleet components (métiers); the actual minimum length limit in catches (current size at first capture) is not modified (set constant at $9 \mathrm{~cm}$ ).

Modification of current size at first capture: the simulations suppose that the different fleets keep their actual level of fishing effort, while their exploitation pattern is changed by setting the fishing mortality to zero for length classes lower than the simulated length.

Fishing closed season regulation: This regulation limits, solely, the access period for trawlers to the fisheries accompanied by increasing their fishing effort. These simulations have been tested because the fishery administration in Oman plans to develop the activities of trawlers (actually only 4-5 trawlers). Keeping their quotas (catch) unchanged, four management scenarios have been tested for trawler period activities; these scenarios suppose a closed season for the trawlers between 3 and 6 months deferring in time. So, quarterly length frequencies have been prepared for these simulations. During closed season periods, catches of trawlers are supposed equal to zero and the corresponding length frequency is removed from the input data base.

\section{RESULTS}

Fishing mortality $F$. Different terminal fishing mortalities $\left(F_{t}\right)$ have been tested to estimate total fishing mortality $(F)$ of Omani $A$. spinifer. The most probable value of $F_{t}$ was considered equal to 0.35 ; this value is close to those of fishing mortalities of the previous lengths (Fig. 2). The fishing mortality averaged across all size classes is 0.1 , but $F$ differs significantly in relation to size. $F$ was low $(<0.10)$ for fish sizes lower than the size at which sexual maturity is attained $(27 \mathrm{~cm})$. Above this size, $F$ increased around 0.16 for size range $30-48 \mathrm{~cm}$ and reached quickly its maximum value of 0.35 for the largest size categories (at fish sizes $\geq 50 \mathrm{~cm}$ ). The low fishing mortality on immature fish $(<27 \mathrm{~cm})$ should be noted; then the exploitation pattern of $A$. spinifer is oriented to the mature fraction of the stock.

To estimate the sensitivity of fishing mortalities to the $M$ value used in this analysis, a value of $M=0.2$ was test-

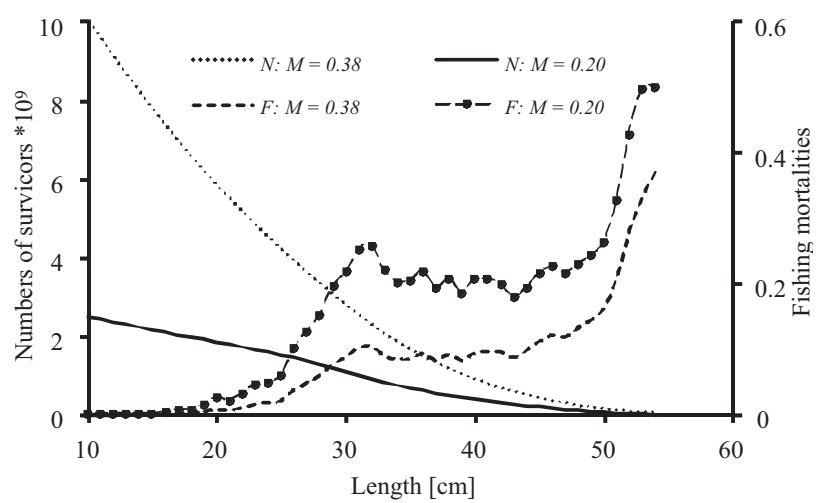

Fig. 2. Fishing mortality profile and survivor numbers, according to the value of M, of Argyrops spinifer in Arabian Sea, Oman ed. The results (Fig. 2) obtained showed a high sensitivity to this parameter. The mean value of $F$ was nearly doubled in the intermediate sizes but the F profile kept the same shape (oriented to adult fraction of the population).

The fishing mortality per fleet component is shown in Fig. 3. The trawl fleet contributed largely to the total fishing mortality of the stock. The hand lines of Al-Wusta region and trawlers targeted largely adult specimens with high fishing mortalities in the length range around $50 \mathrm{~cm}$. In contrast, the fishing traps fleet of Sharqia and Dhofar hand lines targeted primarily the younger fraction of the stock with high fishing mortalities in the length range between 27 and $32 \mathrm{~cm}$. The fishing traps fleet of Dhofar and hand lines of Sharqia catch a mix of adult and young animals.

Recruitment and stock biomass. Recruitment was estimated as the number of fish in the smallest class size, in this case $9 \mathrm{~cm}$, i.e., $10.5 \times 10^{9}$ individuals (Fig. 2). This figure also shows the number of survivors per length class. The proportion of survivors larger than $37 \mathrm{~cm}\left(L_{50}\right)$ is around $20 \%$ of the recruits. The sensitivity of the survivors number to the $M$ value used should be noted (Fig. 2).

\section{Yield per recruit and exploitation pattern.}

(1) Effort regulation. Any increase of the actual fishing effort (effort multiplication $=1$ ) would, in the long-term, lead to an increase of the long-term production (Fig. 4), when the minimum length limit is not modified. An increase of $50 \%$ of the actual fishing effort would lead to a gain of $24 \%$ in long-term yield. A reduction of the effort would, in the long-term, lead to a loss of the production, e.g., an effort reduction of $50 \%$ would result in a decrease of $37 \%$ in long-term yield.

With $M=0.2$, the increase of fishing effort would not improve the long-term catches. In fact, an increase of fishing effort by $50 \%$ would not lead to any significant increase of the actual catches, but the level of the spawning stock biomass (SSB) would decrease from $54 \%$ to around $44 \%$ of the virgin SSB value. Therefore, no increase of actual fishing effort should be considered. In any case, any reduction of fishing effort would lead to an increase in spawning stock biomass (SSB) (Fig. 4).

An increase in total effort would lead to significant long-term gains for all fleet components (Fig. 5) except

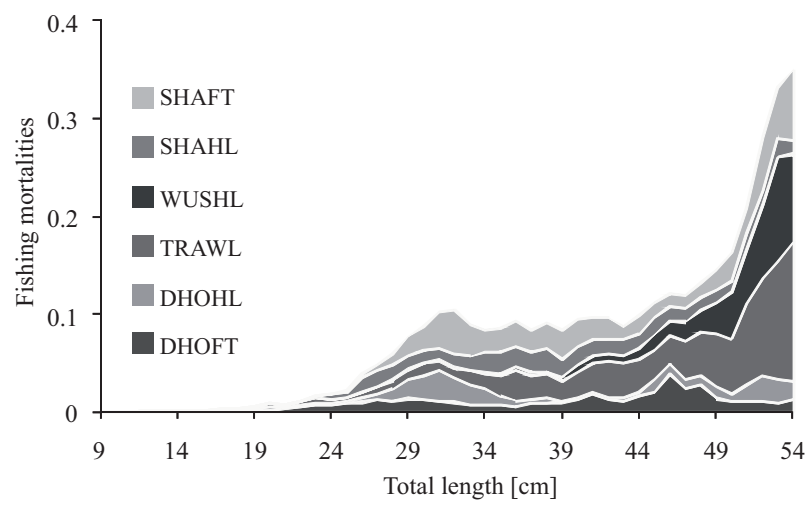

Fig. 3. Fishing mortality profile for the different fishing fleets of Argyrops spinifer in Arabian Sea, Oman 
for the hand line fleet of Al-Wusta (WUSHL). The gains are highest for fleet components that capture the smaller specimens, i.e., the fleet components of Sharqia and Dhofar regions (SHAHL, SHAFT, DHOFT and DHOHL). For example, an increase of 50 percentage points in effort would result in an increase in long-term yield of $32,32,29,27$, and 18 percentage points, for the DHOHL, SHAHL, DHOFT, SHAFT and TRAWL fleets, respectively. For an important increase of effort (double effort) WUSHL would lose around 2 percentage points.

With $M=0.2$, an increase in total effort would only lead to long-term gains for fleet components that capture the smaller specimens, i.e., fleet components in the Sharqia and Dhofar regions while fleets that targeted adults (Al-Wusta and trawlers) would lose out. For an increase of 50 percentage points in effort, the gains are around $16,11,9$, and 7 percentage points for DHOHL, SHAHL, DHOFT, and SHAFT respectively; however, the losses in catch are 27 and 8 percentage points for WUSHL and TRAWL, respectively.

Therefore, if fishing pressure is set to increase substantially, it will be affecting negatively the fleets targeting the adult fraction of the stock and then will affect negatively the pattern of exploitation in the fishery. Then, the increase of effort should be particularly precautionary and exclusively for fleets targeting the adult fraction. In addition, this management measure should be accompanied by

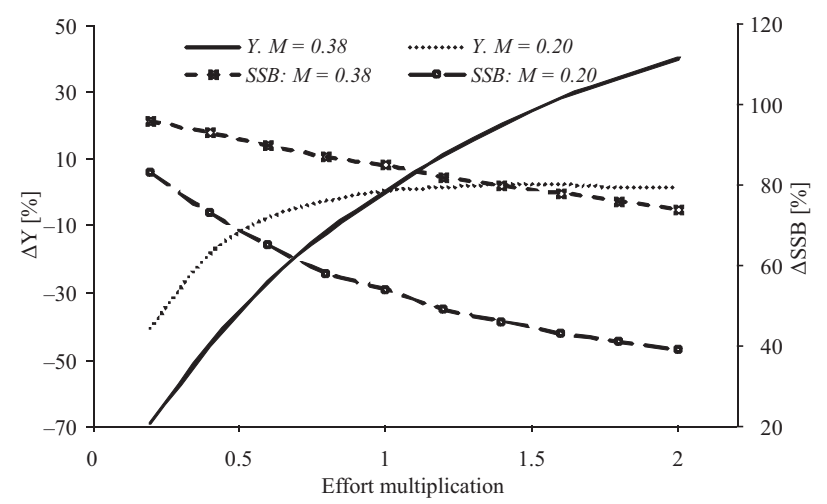

Fig. 4. Relative variations in long-term yield and SSB versus fishing effort, using two values of $\mathrm{M}$, for Argyrops spinifer in Arabian Sea, Oman

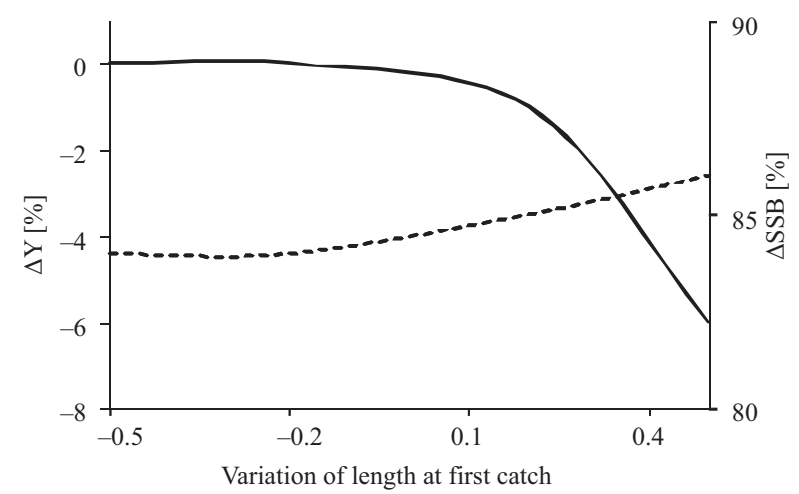

Fig. 6. Changes (\%) in long-term yield and SSB (\%) versus minimum length limit of Argyrops spinifer in Arabian Sea, Oman; $\Delta \mathrm{Y}(\%)$ is the percentage change in yield. $\triangle \mathrm{SSB}(\%)$ is the percentage change in spawning stock biomass a monitoring system of the resources status and an economical study should be carried out in advance of any changes to provide evidence of the sustainability of any economic profitability derived from such an increase in effort.

(2) Size at first capture regulations (Minimum length limit). Keeping the actual fishing effort unchanged, a moderate change (increase/decrease by 20 percentage points) in the length at first capture would not affect substantially the longterm yield (Fig. 6). If the minimum length limit is substantially increased (50 percentage points), the long-term catch will decrease by 13 percentage points. However, the long-term gain in spawning stock biomass of such a measure would be very significant; gains would exceed 15 percentage points.

A moderate change (i.e., an increase/decrease of 20 percentage points) in minimum length limit would not lead to any major modifications of the long-term catches For all fleet components excepting SHAHL that lose around 13 percentage points. An important increase (50 percentage points) of this length would lead, in the long-term, to substantial losses for the hand lines fleets of Sharqia and Dhofar (Fig. 7) while trawlers and fishing traps of Sharqia would gain around 4-5 percentage points from such a measure.

A simulation was, also, performed with a value of $M=0.2$ and the results obtained lead to similar conclusions as using $M=0.38$. So, this regulation is not actually recommended as a management option for the $A$. spinifer fisheries.

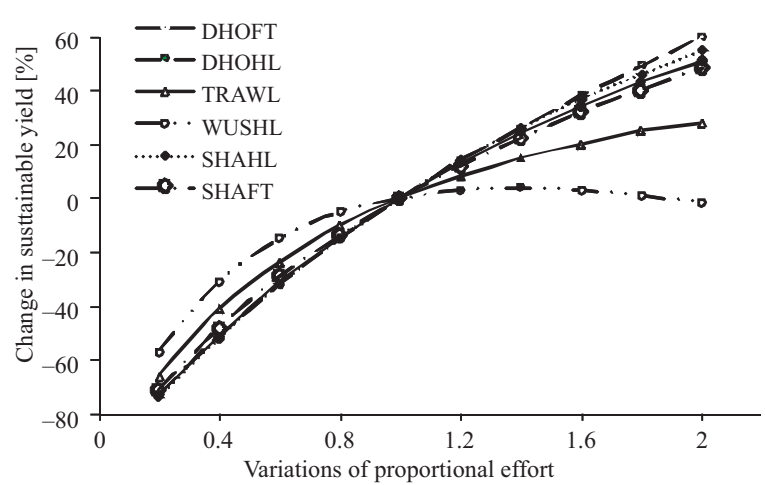

Fig. 5. Relative change in sustainable yield versus fishing effort per fishing fleet of Argyrops spinifer in Arabian Sea, Oman

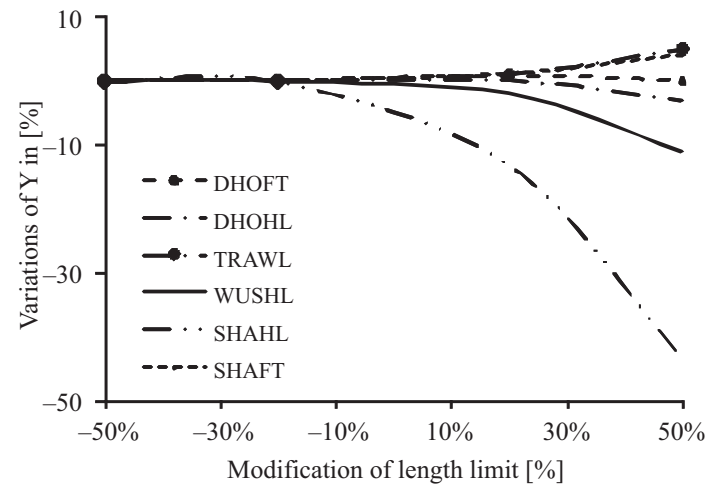

Fig. 7. Relative change in sustainable yield per fishing fleet versus minimum length limit of Argyrops spinifer in Arabian Sea, Oman 
(3) Closed seasons regulations and increasing the fishing effort of trawlers. The managers of the fishery sector in Oman require analyses of the following periods: July-December; October-December; April-June; and April-September.

As a result of the low level of fishing effort for the trawlers, a closed season does not seem to have any significant impact on the total long-term catches. However, if effort is considerably increased, a closed season during April-September would lead to a slightly (marginal) gain in the total long-term catches (Fig. 8). Also, this regulation would, in the long term, lead to the highest gain for the artisanal fleets (Fig. 9) while it affects, in the long term, negatively the catch of trawlers. In contrast, the trawler fleet gains substantially if a closed season is regulated between July-December (Fig. 10).

\section{DISCUSSION AND CONCLUSION}

The level of fishing mortality rate for the A. spinifer stock is, in general, relatively low; the mean value is around 0.1 , and it acts largely on the mature fraction of the stock. The different fleet components investigated contributed at different levels to this fishing mortality. The hand lines fleet of Al-Wusta region and trawlers targeted mainly the larger specimens; the fishing traps fleet of Sharqia and Dhofar hand lines targeted primarily the younger fraction of the stock while the fishing traps of Dhofar and hand lines of Sharqia fleets catch a mix of adult and young animals. The exploitation pattern seems appropriate according to the biological characteristics of the species and it should be preserved by keeping the current selectivity of the fishing gears used in the fishery.

The long-term yield according the fishing effort is very sensitive to the value of natural mortality value used in the analysis. An increase in fishing effort by 50 percentage points would lead, in the long term, to a yield gain of around 15 percentage points if the adopted $M$ value is 0.38 . However, for $M=0.2$, the stock appears to be near to full exploitation status. In the two simulations with different $M$ values, the spawning stock biomass would decrease substantially if the effort is increased considerably. This measure affects negatively the fleet components targeting the adult fraction of the population. So, any increase of the effort should not be recommended.

A moderate increase in the size at first capture does not seem to lead to any significant impact in the long-term yield of $A$. spinifer. Nevertheless, if this length is, substantially, increased a loss in the long term yield would result.

The fishing closed season regulation for trawlers would not affect in the long-term the yield of the stock, but if their effort is considerably increased the appropriate closed season would be from April to September.

The results obtained in this study lead to the same conclusions obtained by Grandcourt et al. (2004) who estimated the exploitation rate $\left(0.407 \cdot\right.$ year $\left.^{-1}\right)$ for $A$. spinifer in the southern Arabian Gulf to that at the estimated safe harvest level $\left(0.401 \cdot\right.$ year $\left.^{-1}\right)$. Also, Edwards et al. (1985) indicated moderate total mortalities $\mathrm{Z}$ (from 0.31 to 0.61 )

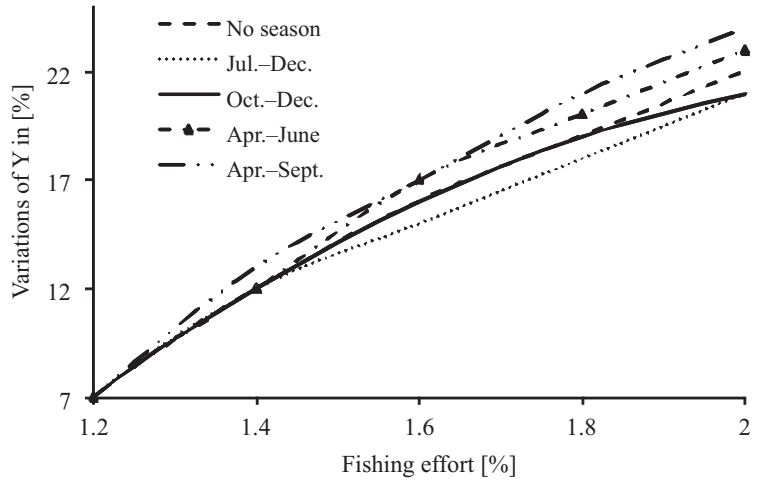

Fig. 8. Impact of a closed season regulation for trawlers on the total long-term catch of Argyrops spinifer in Arabian Sea, Oman; $\Delta \mathrm{Y}(\%)$ is the percentage change in yield

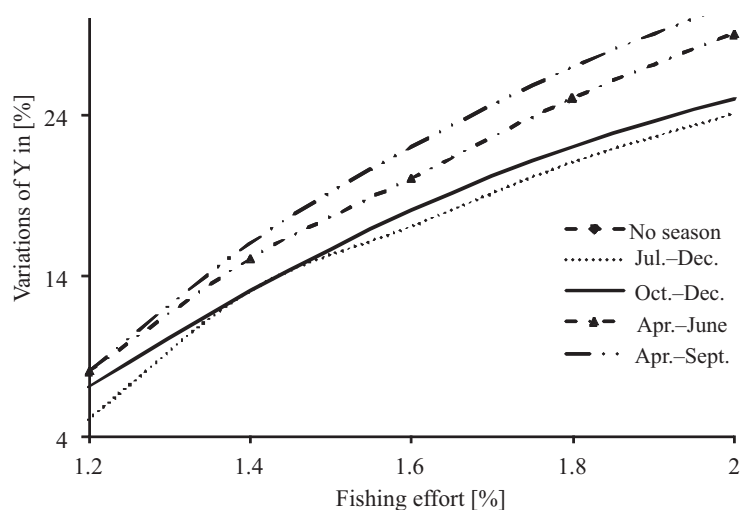

Fig. 9. Impact of a closed season regulation for trawlers on the artisanal long-term catch of Argyrops spinifer in Arabian Sea, Oman; $\Delta \mathrm{Y}(\%)$ is the percentage change in yield

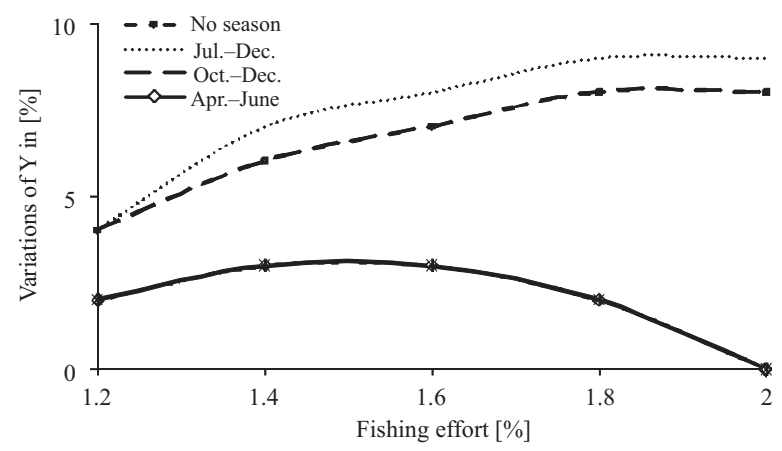

Fig. 10. Impact of a closed season regulation for trawlers on their long term catch of Argyrops spinifer in Arabian Sea, Oman; $\Delta \mathrm{Y}(\%)$ is the percentage change in yield

for 11 species of fish (including A. spinifer) from the Gulf of Aden.

As opposed to the healthy status of $A$. spinifer stock in Arabian Sea (Oman), many fish stocks in this region, are under greater fishing mortalities and suffer from growth overfishing. In fact, Grandcourt et al. (2004) indicated for A. spinifer in the southern Arabian Gulf that the high juvenile retention rate $(66.9 \%)$ and the discrepancies between the mean size at first capture and that which would maximize yield per recruit, suggest that the existing mesh size regulations in the trap need to be reviewed. Devaraj 
and Vivekanandan (1999) indicated inappropriate exploitation patterns for most of the exploited stocks in Indian fisheries; they have shown fishing mortality coefficients higher than those for natural mortality. Recently, Biju Kumar and Deepthi (2006) pointed out that the impact of trawling leads to a considerable by catch and that this is major concern affecting the sustainability of marine fisheries. Mohamed and Zacharia (2007) indicated that the key resources from the Arabian Sea of Karnataka (India) showed rapid decline in yields within 5 years due to a consistent increase of fishing effort between $20 \%$ and $100 \%$.

Unfortunately, no study on the dynamic stock of A. spinifer fisheries in the Arabian Sea (Oman) has been previously carried out to which our results can be compared and discussed. These results constitute the first investigation of the exploitation pattern and potential management options of the Omani A.spinifer fisheries that have been conducted at a relatively early stage of its fishing development (history). More investigations should be carried out in order to monitor the evolution of the fishery and to identify eventual stock units and operational management units. It is not excluded that the A. spinifer populations in the Arabian Sea could constitute two distinguished management units (stocks); one in the east (Sharqia and Al Wusta regions) and the second in the south (Dhofar region). In this case, data collected should be analyzed separately.

\section{ACKNOWLEDGEMENTS}

This study was financially supported by the Fisheries Research Fund of the Sultanate of Oman. Authors would like to thank Dr. M. Redha, Dr. Y. Al-Akzami and Dr. S. Al-Habsi for their advice and support of the project. We also express our sincere thanks to the staff of the Marine Science and Fisheries Center for their help. This project was fully funded by the Fisheries Research Fund of Oman.

\section{REFERENCES}

Al-Mamry J.M., McCarthy I.D., Richardson C.A., Ben Meriem S. 2009. Biology of the kingsoldier bream (Argyrops spinifer, Forsskål 1775; Sparidae) from the Arabian Sea, Oman. Journal of Applied Ichthyology 25 (5): 559-564. DOI: 10.1111/j.1439-0426.2009.01260.x.

Anonymous 2002. Annual statistics report for 2001 for the Sultanate of Oman. Department of Fisheries statistics, Directorate General of Fisheries Resources, Ministry of Agriculture and Fisheries, Muscat, Sultanate of Oman.

Anonymous 2003. Annual statistics report for 2002 for the Sultanate of Oman. Department of Fisheries statistics, Directorate General of Fisheries Resources, Ministry of Agriculture and Fisheries, Muscat, Sultanate of Oman.

Ben Meriem S., Al-Marzouqi A., Al-Rassadi E., Al-Mamry J. 2004. Age and growth of croaker, spangled emperor, soldierbream, brownspotted grouper, largehead hairtail, mullet, and cuttlefish. Demersal Project 1. Ministry of Agriculture and Fisheries, Sultanate of Oman. Technical Report 6/2004.

Ben Meriem S., Al-Nahdi A., Al-Mamry J., Al-Marzouqi A. 2002a. Spawning season and size at maturity of croaker, spangled emperor, soldierbream, brownspotted grouper, largehead hairtail, mullet and cuttlefish. Demersal Project 1. Ministry of Agriculture and Fisheries, Sultanate of Oman. Technical Report 3/2002.

Ben Meriem S., Al-Waili H., Al-Mamry J., Al-Mazrouei A. 2002b. Biometric characters of croaker, spangled emperor, soldierbream, brownspotted grouper, largehead hairtail, mullet, and cuttlefish. Demersal Project 1. Ministry of Agriculture and Fisheries, Sultanate of Oman. Technical Report 4/2002.

Biju Kumar A., Deepthi G.R. 2006. Trawling and by-catch: Implications on marine ecosystem. Current Science 90 (7): 922-931.

Devaraj M., Vivekanandan E. 1999. Marine capture fisheries of India: Challenges and opportunities. Current Science 76 (3): 314-332.

Chevaillier P., Laurec A. 1990. Logiciels pour l'évaluation des stocks de poisson. FAO, Document Techniques des Pêches, 101 (Supplement 4) 122 pp.

Edwards R.R.C., Bakhader A., Shaher S. 1985. Growth, mortality, age composition and fisheries yields of fish from the Gulf of Aden. Journal of Fish Biology 27 (1): 13-21. DOI: 10.1111/j.1095-8649.1985.tb04005.x.

Grandcourt E.M., Al Abdessalaam T.Z., Francis F., Al Shamsi A.T. 2004. Biology and stock assessment of the sparids, Acanthopagrus bifasciatus and Argyrops spinifer (Forsskål, 1775), in the southern Arabian Gulf. Fisheries Research 69 (1): 7-20. DOI: 10.1016/j.fishres.2004.04.006.

Jones B. 1974. Assessing the long-term effects of changes in fishing effort and mesh size from length composition data. International Council for the Explororation of the Seas, CM 1974/F 33.

Jones R. 1981. The use of length composition data in fish stock assessment (with note on VPA and cohort analysis). FAO Fisheries Circular 734.

McIlwain J., Hermosa G.V., Claereboudt M., Al Oufi H.S., Al Awi M. 2006. Spawning and reproductive patterns of six exploited finfish species from the Arabian Sea, Sultanate of Oman. Journal of Applied Ichthyology 22 (2): 167-176. DOI: $10.1111 /$ j.1439-0426.2006.00723.x.

Mohamed K.S., Zacharia P.U. 2009. Prediction and modelling of marine fishery yields from the Arabian Sea off Karnataka using Ecosim. Indian Journal of Marine Sciences 38 (1): 69-76.

Pauly D. 1980 . On the interrelationships between natural mortality, growth parameters and mean environmental temperature in 175 fish stocks. Journal du Conseil International pour L'Exploration de la Mer. 39 (3): 195-212.

Pereiro J.A., Pallares P. 1984. Consequences of introducing errors in the values of the input parameters in the length distribution analysis. As applied to the northern stock of hake. International Council for the exploration of the Seas C.M. 1984/G 61 .

Randall J.E. 1995. Coastal fishes of Oman. University of Hawaii Press, Honolulu, HI, USA.

Sparre P., Venema S.C. 1992. Introduction to tropical fish stock assessment. Part 1-manual, FAO Fisheries Technical Paper (306) Rev. 1.

Received: 16 March 2009

Accepted: 24 August 2010

Published electronically: 25 March 2011 